\title{
MEMBANGUN INTEGRASI DATA STAGING DAN DATA MART PADA PERUSAHAAN XYZ
}

\author{
Muhammad Firdaus ${ }^{1}$, Shedriko ${ }^{2}$ \\ ${ }^{1,2}$ Universitas Indraprasta PGRI \\ TB. Simatupang, Jl. Nangka Raya No. 58 C \\ 12dasurichi@gmail.com, ${ }^{2}$ shedriko@gmail.com
}

\begin{abstract}
ABSTRAK
Selama pandemi COVID-19 berlangsung, sebagian masyarakat dituntut untuk menjalankan aktivitasnya di rumah, tidak terkecuali untuk karyawan di perusahaan XYZ, dimana sebagian besar karyawannya pun diharuskan menjalankan kewajiban dan tanggung-jawabnya dirumah masing-masing agar proses bisnis perusahaan tetap berjalan dengan baik. Teknologi informasi dituntut agar bisa mengintegrasikan semua data yang telah di input oleh user, sehingga nanti dapat menjadi informasi yang berguna bagi manajemen. Data Staging dan Data Mart digunakan oleh user, agar bisa memilah data mana saja yang diperlukan, dan digunakan agar nantinya dapat diolah kembali oleh aplikasi DSS (Decision Support System) sehingga hasil keluaran informasi akhir bisa menjadi bahan pertimbangan oleh pihak pengambil keputusan. Dalam merancang dan membangun integrasi Data Staging dan Data Mart diperlukan metode yang tepat dalam mencapai hasil akhir yang sesuai dengan harapan user, dan hal ini metode Extreme Programming masih dianggap paling tepat dalam menjalankan proyek ini. Hasil akhir dari penelitian ini berupa rancang bangun ETL (Extract-Transform-Load) yang dapat mengolah data dari berbagai sumber, sehingga menjadi data akhir yang nantinya dapat di konsumsi oleh aplikasi DSS maupun MIS (Management Information System) di perusahaan XYZ.
\end{abstract}

Kata Kunci: Data, Informasi, Integrasi, Data Staging, Data Mart

\begin{abstract}
During the COVID-19 pandemic, some people are required to carry out their activities at home, including employees at XYZ company, where most of them are carred out their obligations and responsibilities at home so that the company's business processes continue to run well. Information technology is required to be able to integrate all data that has been inputted by the user, so that later it can become useful information for management. Data Staging and Data Mart are used by users, so they can sort out which data is needed, and used so that later it can be processed again by the DSS (Decision Support System) application so that the final information output can be taken into consideration by decision makers. In designing and building a Data Staging and Data Mart, the right method is needed to achieve the end of result that is in accordance with user expectations, and this is the Extreme Programming method is still considered the most appropriate in carrying out of this project. The final result of this research is an ETL (Extract-Transform-Load) design that can process data from various sources, so that it becomes the final data that can later be consumed by DSS and MIS (Management Information System) applications at company XYZ.
\end{abstract}

Key Word: Data, Information, Integration, Data Staging, Data Mart.

\section{PENDAHULUAN}

Teknologi internet dituntut agar bisa memenuhi kebutuhan masyarakat yang mengharuskan bekerja dirumah atau istilahnya dalam bahasa asing yaitu Work from Home (WFH). Walaupun Sebagian masyarakat belum bisa menyesuaikan diri dengan keadaan akibat dampak dari pandemi tersebut. Tetap dengan menerapkan $5 \mathrm{M}$ : mencuci tangan, menggunakan masker, menjaga jarak, menjauhi dari kerumunan, serta mengurangi mobilitas. Mau tidak mau mereka terpaksa hidup berdampingan dengan keadaan. Situasi tersebut menjadikan internet sebagai primadona dalam menjalankan aktivitas walaupun sedang berada di rumah.

Setiap harinya user input data setiap transaksi yang masuk maupun keluar, serta setiap bulannya pihak bank juga mempersiapkan laporan agar bisa tercatat di Bank Indonesia. Data yang telah diinput tersebut nantinya akan diolah dan dimanipulasi sedemikian rupa agar bisa sesuai dengan tujuan dan kebutuhan user. Data yang telah dimanipulasi atau kami sebut dengan istilah "Data Setengah Matang" tersebut pun tidak serta merta langsung digunakan oleh user, tetapi harus ditempatkan 
terlebih dahulu di server basis data tersendiri agar nantinya data tersebut bisa diolah kembali di kemudian hari. Saat ini user melakukan pelaporan dalam bentuk format text file yang sebelumnya hasil olahan dari file spreadsheet serta berbagai sumber data utama perusahaan. Setiap kali user secara manual edit perubahan, penambahan, serta penggabungan data dengan menggunakan aplikasi spreadsheet sebelum akhirnya di ekspor kedalam bentuk text file, dan konten dari text file tersebut disisipkan kedalam format template BI (Bank Indonesia) sebelum akhirnya di input kedalam aplikasi khusus yang telah disediakan oleh BI sebagai regulator.

Tidak banyak orang yang tahu mengapa diperlukan area data staging, di satu sisi pentingnya integrasi data sehingga data yang dikumpulkan, dan diolah tidak menjadi data yang tidak memiliki arti dikarenakan data yang disimpan masih berbentuk pulau-pulau (data islands). Menurut Ashraf (ASHRAF, 2020), dipertimbangkannya adanya lapisan (layer) data staging adalah karena perlunya integrasi antara data yang satu dengan yang lain, dimana data yang diproses bervariasi dalam jumlah yang sangat besar. Suatu pendekatan akan integrasi data maka perlunya data tersebut diekstrak (Extract) terlebih dahulu, kemudian dirubah (Transform), dan dimuat/diproses (Load) ke dalam tempat penyimpanan yang baru, sehingga nanti data yang disimpan di area staging dapat dengan mudah dirubah, di manipulasi, maupun ditambahkan sesuai dengan kebutuhan user, sebelum nantinya data tersebut diproses berikutnya kedalam data warehouse, data mart atau bisa langsung di konsumsi oleh aplikasi lainnya.

Area data Staging sendiri berada di lapisan (layer) menengah antara sumber data dan data target atau dikenal dengan istilah Landing Zone. Seringkali data warehouse, data mart atau tempat penyimpanan data sementara lainnya menampung data dari berbagai macam sumber dari sistem RDBMS dengan memuat berbagai bentuk dan dimensi data yang beredar. Secara dasar area data ini sangat diperlukan agar dapat menampung data, membersihkan data, ataupun menggabungkan data sedemikian mungkin sehingga nantinya bisa ditempatkan kedalam data warehouse
(Reddy, 2017). Infrastruktur di perusahaan ini pun memungkinkan agar pembangunan data staging dan data mart bisa terealisasi dengan baik, mengingat banyaknya sumber data yang dimiliki serta banyaknya pulau-pulau data yang beredar, dapat menjadi solusi terbaik dalam mencegah tidak konsistensinya dalam memelihara data itu sendiri.

Informasi yang relevan bagi user dalam mengambil keputusan serta mendukung pembuatan laporan dan analisis data pada unit bagian operasional, hal tersebut tersimpan didalam server data mart (Anggraeni, Mustikasari, \& Wibawa, 2016). Perusahaan telah menginvestasikan sejumlah besar dana anggaran untuk dapat merealisasikan pembangunan server data staging dan data mart. Namun hal ini belum efektif penggunaannya apabila belum di integrasikan kedua server tersebut.

Penulis mengambil solusi atas permasalahan yang dihadapi tersebut dari pengalaman implementasi membangun integrasi antara data staging dan data mart, dengan menggunakan perangkat lunak Microsoft SSIS (SQL Server Integration Service), serta Microsoft Visual Studio 2017 sebagai piranti untuk merancang bangun alur data dari sumber menuju target server basis data yang dituju, sedangkan untuk memanipulasi, merubah, serta menggabungkan data dari beberapa sumber, penulis disini menggunakan perangkat lunak SQL Server Management Studio versi 2016. Penggunaan SSIS sendiri merupakan suatu bentuk optimisme kami agar dapat mengintegrasikan sumber data yang sangat bervariasi, serta mencegah terjadinya kegagalan dalam proses ETL (ExtractTransform-Load) yang diakibatkan adanya masalah yang terjadi di sumber data yang dimiliki perusahan ini (Nugroho, 2018), seperti misalnya: data tidak konsisten, tidak terbentuknya normalisasi data, maupun duplikasi data yang sering menjadi momok, ketika dilakukan pemetaan menggunakan query SQL.

\section{METODE PENELITIAN}

Untuk mencapai tujuan (Goal) dalam menyelesaikan proyek ini, maka diperlukan strategi yang tepat, dan metode yang tepat untuk mencapai target tersebut maka saya gunakan metode Extreme Programing (XP). 
Hal ini dikarenakan untuk menyesuaikan antara kebutuhan user, waktu dan tenaga ahli yang dibutuhkan, sehingga proyek bisa selesai tepat pada waktunya. Metode ini merupakan pendekatan berorientasi obyek dan sasaran dari metode ini adalah dengan memanfaatkan anggota proyek yang dibentuk dalam skala kecil sampai medium serta metode ini juga menyesuaikan diri dengan situasi / kondisi dimana kebutuhan user semakin berjalannya waktu yang semakin tidak jelas maupun terjadi perubahan-perubahan mendadak yang sangat cepat, tetapi dituntut harus tepat dalam pencapaiannya (Supriyatna, 2018).

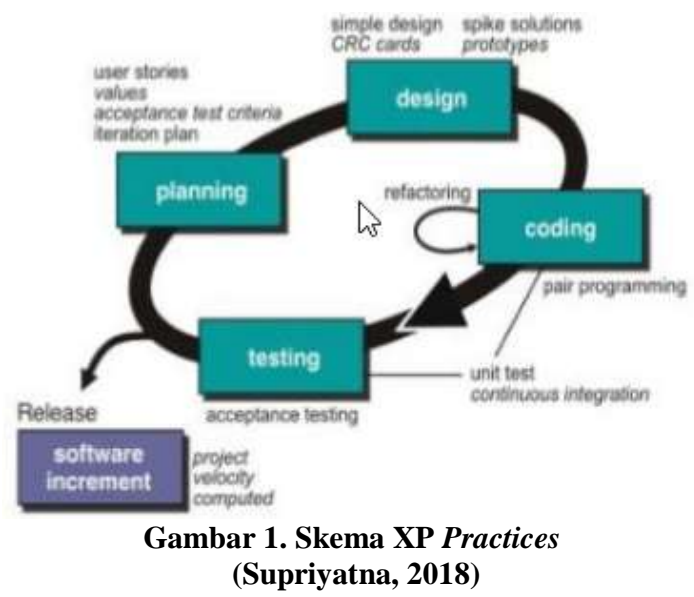

Adapun tahapan pembangunan integrasi data staging dan data mart pada perusahaan XYZ adalah sebagai berikut:

\section{Perencanaan (Planning)}

Pada tahapan ini dimulai dengan mengumpulkan informasi mengenai kebutuhan user ke dalam dokumen BRD (Business Requirement Document), dimana memuat latar belakang masalah, sumber data yang saat ini digunakan, kondisi perangkat keras dan perangkat lunak yang digunakan, sistem informasi yang sedang berjalan, sampai dengan tenggat waktu yang perlu diperhatikan oleh tim dalam menyelesaikan proyek ini.

\section{Perancangan (Design)}

Pada tahapan ini tim mulai menggali informasi dengan mengumpulkan data - data observasi serta mempelajari dokumentasi pemetaan data dari sumber sampai ke target data pelaporan user. Setelah selesai maka tim segera mendokumentasikannya ke dalam dokumen FSD (Functional Specification Document) dan dokumen Pemetaan Query
(Query Mapping). Di dalam dokumen FSD, tim menjabarkan secara rinci arus data dari sumber ke target ke dalam diagram Flowchart, menggambarkan kebutuhan perangkat keras ke dalam diagram arsitektur, serta menjabarkan secara rinci Sistem Informasi yang digunakan serta strategi integrasi data yang akan diusulkan. Pada dokumen Pemetaan Query, tim akan menjabarkan secara rinci peta logik query beserta peta data sumber maupun target.

\section{Pengkodean (Coding)}

Dalam tahapan ini tim membuat kode (script) sesuai dengan Pemetaan Query yang telah dilakukan sebelumnya. Pembuatan kode menggunakan bahasa pemograman SQL dengan didukung 2 perangkat lunak, yaitu SQL Server Management Studio (SSMS) dan Visual Studio. SSMS digunakan untuk membangun kode query dan disimulasikan dengan membentuk tabel data target sementar yang dibutuhkan oleh user, sedangkan Visual Studio digunakan untuk mengintegrasikan data yang sudah terbentuk dengan mengekstraksi (Extract) data dari sumber (yang diambil dari Data Warehouse maupun kanal data di setiap satelit aplikasi yang digunakan oleh user), kemudian dimuat/diproses (Load) ke dalam tabel Data Staging dan kemudian dirubah (Transform) kedalam bentuk data yang diperlukan oleh user sehingga akhir data tersebut disimpan ke dalam Data Mart.

\section{Pengujian (Testing)}

Setelah selesai dengan membangun kode yang dibutuhkan, pada tahapan ini dilakukan pengujian dengan 3 langkah pengujian, yaitu pengujian disetiap unit (Unit Test), pengujian dengan mengacu pada setiap integrasi sistem informasi yang sudah ada sebelumnya (Sistem Integration Test), dan terakhir pengujian dengan melibatkan user dalam menentukan apakah solusi yang sudah dibuat oleh tim sudah sesuai dengan kebutuhan user atau tidak (User Acceptance Test). Apabila ternyata teridentifikasi bugs atau kesalahan dalam menampilkan data laporan baik dari sisi pengelompokan data ataupun posisi data pada tabel target, maka tim segera menginvestigasi lebih lanjut dan kembali ke tahapan pengkodean untuk diperbaiki dengan cepat dan tepat (Factor, 2020). 
Rilis dan Peningkatan Perangkat Lunak (Release dan Software Increment)

Pada tahap ini atau disebut "Tahap Produksi Akhir", solusi akhir yang telah selesai di uji dengan 3 langkah pengujian dan tidak ada lagi temuan atau bugs pada solusi ataupun permasalahan baik pada perangkat keras maupun perangkat lunak pendukung, maka siap untuk dirilis ke lingkungan Produksi. Setelah selesai dirilis, maka akan diuji secara keseluruhan dengan melihat dampak atau imbas yang terjadi ketika di integrasikan secara nyata dengan kondisi lingkungan sebenarnya dan dengan sistem informasi yang sudah terpasang atau tersedia di lingkungan tersebut (Eby, 2018).

\section{HASIL DAN PEMBAHASAN}

Berdasarkan alur siklus proyek pada skema XP Practice (Gambar 1), maka berikut hasil pembahasannya:

\section{Perencanaan (Planning)}

Hasil identifikasi masalah tertuju pada perubahan strukturisasi model bisnis perusahaan yang berdampak pada pola pikir user / pengguna dimana sebelumnya masih menginput data yang diperoleh dari Data Warehouse kemudian di proses dan diolah lebih lanjut menggunakan spreadsheet. Sebelumnya mereka mempertimbangkan kemudahan, serta banyaknya tenaga ahli yang mahir menggunakan perangkat lunak tersebut, namun seiringnya waktu, dan bertambahnya pula data yang diproses, sehingga berdampak pada lambatnya proses data sampai ke dalam bentuk laporan (kurang lebih 15 - 30 menit), serta belum lagi usangnya perangkat keras dan perangkat pendukung yang digunakan.

\section{Perancangan (Design)}

Dari hasil diskusi dengan user dan mempelajari dari dokumen-dokumen pemetaan logika query yang sudah dibuat, di dapat informasi bahwa data-data dari sumber $\mathrm{X}$ yang diambil dari inti perusahaan (Core Banking) ditempatkan terlebih dahulu di Data Warehouse, dan kemudian di ekstrak dan dimuat secara as is kedalam tabel $\mathrm{X}$ source dan kemudian diproses berdasarkan peta logika kebutuhan user (dengan menggabungkan input dari beberapa tabel parameter), sehingga dibentuk dan dimuat ke dalam table Y Form. Tabel tersebut nantinya akan di ubah dan dimuat ke dalam tabel-tabel yang dibutuhkan untuk pelaporan di dalam basis data Data Mart, dan kemudian Sistem Informasi Pelaporan akan mengkonsumsi data-data tersebut guna untuk keperluan Laporan Harian Bank Umum.

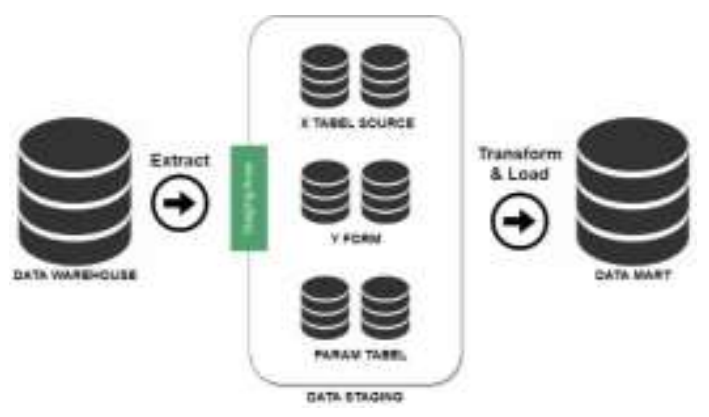

Gambar 2. Diagram Flowchart Pembentukan Data Pelaporan Y Form

Untuk memenuhi ketersediaan data selama proses berlangsung, maka diperlukan Rencana Pemulihan Bencana (Disaster Recovery Plan) dengan mengusung strategi infrastruktur failover Server Produksi dengan Server DRC, guna hal ini sebagai media mitigasi resiko dan pemulihan setelah terjadinya bencana yang kemungkinan terjadi (Brush \& Crocetti, 2020).

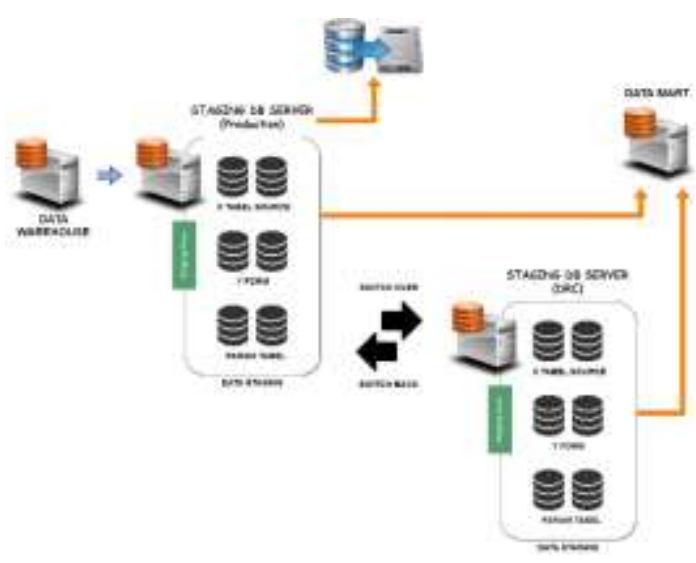

Gambar 3. Diagram Arsitektur Infrastruktur Failover

Dengan melihat beban proses yang ditanggung pada saat mengolah data yang di esktrak sebelumnya dari server Data Warehouse serta beban biaya yang ditanggung oleh user dalam memenuhi kebutuhannya, maka diambil keputusan bahwa strategi ini hanya diterapkan di lingkungan Staging Area, sehingga akan 
meminimalisir resiko yang akan terjadi di lain hari.

\section{Pengkodean (Coding)}

Pada tahapan ini diperlukan perangkat lunak yang mampu untuk merancang, menguji, dan mengeksekusi data yang telah diperoleh dari Data Warehouse, sehingga hasil simulasi yang dilakukan lebih akurat. Pengkodean dimulai dengan membangun struktur query yang bisa diterjemahkan kedalam bahasa basis data, dan disimulasikan ke dalam perangkat lunak integrasi data (Ikechukwu, 2020). Kode yang telah terbentuk tersebut kemudian dipetakan dengan logika kebutuhan user, dan dijabarkan ke dalam tabel Pemetaan Data Y Form (seperti pada tabel dibawah ini).

Tabel 1. Pemetaan Data Y Form

\begin{tabular}{|c|c|c|c|c|}
\hline \\
\hline \multirow{2}{*}{\multicolumn{5}{|c|}{ 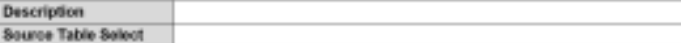 }} \\
\hline & & & & \\
\hline \multicolumn{5}{|c|}{ Solbetion Crthrita } \\
\hline \multicolumn{5}{|c|}{ Special Cosedition } \\
\hline \multicolumn{5}{|c|}{ Musping Oonst } \\
\hline \multicolumn{2}{|c|}{ Destination Flivid } & \multicolumn{3}{|c|}{ asts froen Tatis $Y$ Form } \\
\hline no & Fet tanes & Fine Mans: & 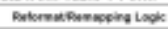 & Sempow vent \\
\hline \multirow{2}{*}{\multicolumn{5}{|c|}{ (1) }} \\
\hline & & & & \\
\hline \multicolumn{5}{|l|}{3} \\
\hline 4 & & & & \\
\hline - & & & & \\
\hline
\end{tabular}

Setelah data telah selesai disimulasikan, maka setiap SSIS package yang telah terbentuk kemudian dipanggil melalui SQL Server Agent, dimana perangkat lunak merupakan fitur bagian dari SSMS.

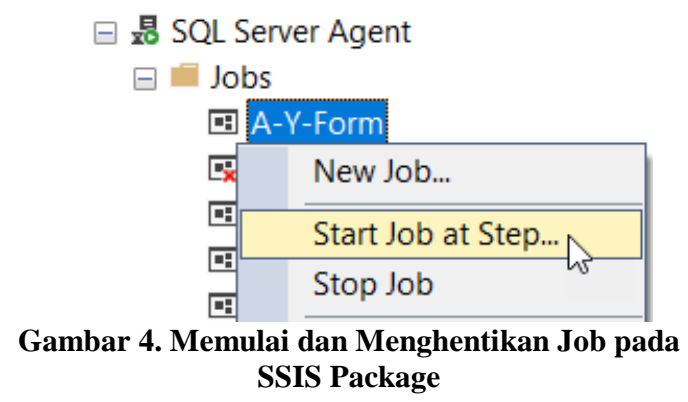

SSIS package tersebut dijalankan melalui perangkat lunak agent secara terjadwal 5 menit sekali, mulai pagi dari jam 8 sampai dengan jam 23:59. Setibanya data tersebut sampai di server Data Mart, setiap 5 menit sekali pula Sistem Informasi Pelaporan akan mengkonsumsi data yang sudah diberikan sampai jam kerja perusahaan telah usai. Secara bersamaan, user pun juga mempersiapkan laporan harian dari hasil keluaran aplikasi tersebut, sehingga nanti akan dilaporkan ke Bank Indonesia sesuai dengan regulasi dan ketentuan yang telah ditetapkan. Dari setiap proses yang telah berjalan, hal ini sudah di catat kedalam data log yang bisa di monitor melalui perangkat lunak Log File Viewer (Anuraag, 2020).

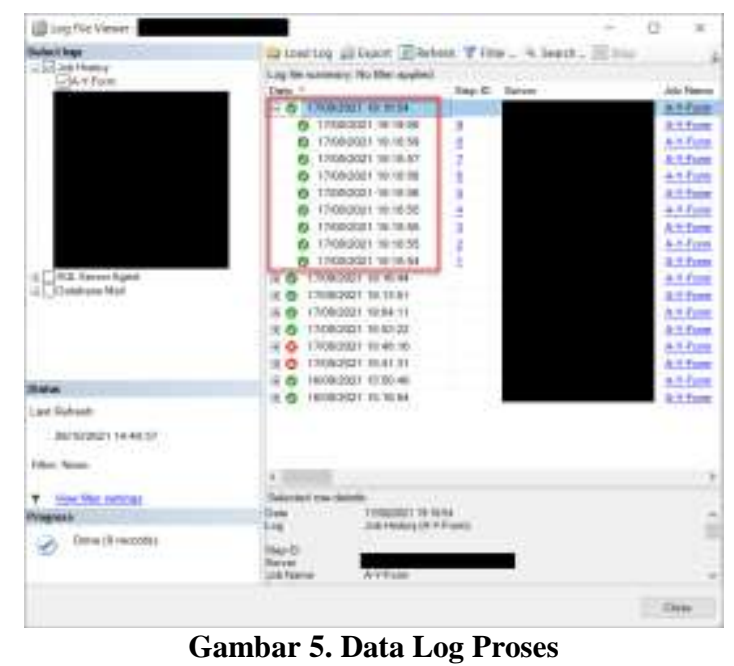

Berhasil atau tidaknya suatu proses yang berjalan, serta pesan error yang muncul dapat ditampilkan secara detail menggunakan perangkat lunak tersebut (lihat pada Gambar 5). Sehingga masalah tersebut bisa di investigasikan lebih lanjut oleh tim internal TI (Teknologi Informasi) Bank.

\section{Pengujian (Testing)}

Pada tahapan ini dimulai dengan Unit Test, dimana tahap ini seorang BA (Business Analyst) berperan besar dalam menguji secara keseluruhan, mulai dari pembentukan data tabel $\mathrm{X}$ source, data $\mathrm{Y}$ form, sampai data yang dikonsumsi secara tepat dengan menggunakan Sistem Informasi Pelaporan. Tahap berikutnya, secara alur proses pengujian masih sama dengan tahap sebelumnya, namun dengan data yang diperoleh dari sumber data dummy internal server bank tersebut, serta sama halnya dengan tahap pengujian terakhir, namun yang membedakan bahwa pengujian dilakukan oleh user sendiri dengan data acak yang diperoleh dari basis data inti perusahaan (Core Banking).

Setiap temuan yang didapat oleh user selama pengujian berlangsung, akan dicatat dan diserahkan ke tim kami, untuk di investigasi dan diperbaiki. Setelah perbaikan pengkodean selesai dan juga telah diaplikasikan ke setiap lingkungan server (mulai dari lingkungan pengembangan, SIT, maupun UAT), selanjutnya tim akan dokumentasikan 
kedalam dokumen User Guide, dan diserahkan ke user untuk diujikan kembali sampai user telah setuju dengan hasil perbaikan tersebut.

\section{Rilis dan Peningkatan Perangkat Lunak} (Release dan Software Increment)

Pada tahapan ini, tim perlu mempersiapkan terlebih dahulu keseluruhan SSIS package versi terakhir yang sudah lolos pengujian, beserta cara dan petunjuk rilis, serta rencana mitigasi resiko yang dituangkan kedalam dokumen Rencana Implementasi. Dokumen tersebut harus dikaji terlebih dahulu dengan internal TI Bank, sebelum ditanda-tangani oleh kedua belah pihak. Apabila dokumentasi telah selesai, maka SSIS Package siap untuk dirilis ke dalam lingkungan Produksi. Dimana di lingkungan tersebut sudah terhubung dengan satelit Sistem Informasi yang ada di Bank tersebut.

Selesainya dirilis, user perlu melakukan pengecekan terakhir, sebelum SQL Server Agent menjalankan proses ETL secara terjadwal setiap harinya. Langkah - Langkah tersebut bukanlah Langkah tersebut Ketika tahap Rilis telah selesai, namun selama solusi telah berjalan, user seringkali melakukan permintaan akan perubahan alur proses pengambilan data ataupun penambahan ruang lingkup pekerjaan akibat dampak dari perubahan regulasi yang diterapkan oleh Bank Indonesia.

Tim pun cepat tanggap memenuhi permintaan user tersebut dengan memaparkan setiap perubahan atau penambahan yang diinginkan oleh user tersebut kedalam dokumen CR (Change Request). Di dokumen ini akan tercatat setiap permintaan tersebut beserta perkiraan waktu, biaya, dan tenaga yang dibutuhkan untuk memenuhi kebutuhan user tersebut. Apabila telah selesai, dan disetujui oleh user, maka akan berlanjut pada tahapan Perancangan, Pengkodean, Pengujian, sampai ke tahap Rilis dan Peningkatan Perangkat Lunak dan seterusnya.

\section{SIMPULAN DAN SARAN}

Solusi integrasi data yang kami terapkan di perusahaan tersebut, serta metode penelitian yang kami gunakan merupakan solusi terbaik dengan mempertimbangkan terhadap masalah - masalah yang terjadi di waktu yang akan datang dengan cakupan aspek permintaan user yang terus bertambah dan berubah-ubah sesuai dengan perubahan alur proses kegiatan bisnis perusahaan.

Melihat akan hal tersebut, solusi ini perlu diperbaiki atau ditingkatkan ke tingkatan yang lebih sempurna, sehingga dari segi kinerja dan kerja sama tim, penguasaan masalah dan lingkungan bisa ditangani lebih baik lagi.

\section{UCAPAN TERIMAKASIH}

Mengingat pengalaman kami selama proyek berlangsung, serta suka duka yang telah dihadapi, kami ucapkan terima kasih sebesarbesarnya Kepada Allah SWT atas karunia yang telah diberikannya, serta tak lupa juga kepad tim kami dilapangan yang telah bekerja dengan baik, siang dan malam tanpa henti, sehingga proyek ini selesai tepat pada waktunya.

Ucapan Terima Kasih disajikan secara singkat sebagai bentuk apresiasi terhadap pihak-pihak meliputi Lembaga pemberi dana, mitra kerja, dan perorangan yang berkontribusi dalam penelitian ini.

\section{DAFTAR PUSTAKA}

Anggraeni, D. T., Mustikasari, M., \& Wibawa, C. (2016). PERANCANGAN DATA MART PADA PERUSAHAAN MANUFAKTUR ALAT PERKANTORAN BAJA. Jurnal Teknologi Rekayasa, 21, 11-21.

Anuraag. (2020). Ingenious Guide to View Log File of SQL Server. SysTools. Retrieved from https://www.systoolsgroup.com/howto/view-log-file-of-sql-server/

ASHRAF, S. (2020). Data Staging Area: How It Solves Data Quality Issues. Retrieved from DataIntegrationInfo website: https://dataintegrationinfo.com/dataintegration-staging-area/

Brush, K., \& Crocetti, P. (2020). disaster recovery plan (DRP). TechTarget. Retrieved from https://searchdisasterrecovery.techtarget .com/definition/disaster-recovery-plan

Eby, K. (2018). Everything You Need to Know to Master Release Management. Smartsheet Contributor. Retrieved from https://www.smartsheet.com/releasemanagement-process 
Factor, P. (2020). UAT, Unit, Integration \& Regression Testing - Database Testing Types. Studio3t.Com. Retrieved from https://studio3t.com/knowledgebase/articles/database-testingregression-integration-unit-uat/

Ikechukwu, L. (2020). The Self-Taught Developer's Guide to Learning How to Code. Freecodecamp.Org. Retrieved from https://www.freecodecamp.org/news/th e-self-taught-developers-guide-tocoding/

Nugroho, K. B. (2018). Pengembangan Data Warehouse Penerimaan Mahasiswa Baru Untuk Informasi Strategik Pada Universitas BSI. Jurnal Kajian Ilmiah, 18(2), 168. https://doi.org/10.31599/jki.v18i2.293

Rama C. Reddy. (2017). What is Staging area and why we need it in DWH? Retrieved from wordpress.com website: https://ramareddydcp.wordpress.com/20 17/02/12/what-is-staging-area-andwhy-we-need-it-in-dwh/

Supriyatna, A. (2018). Metode Extreme Programming Pada Pembangunan Web Aplikasi Seleksi Peserta Pelatihan Kerja. Jurnal Teknik Informatika, 11(1), 1-18. https://doi.org/10.15408/jti.v11i1.6628 